Supplement of The Cryosphere, 12, 3439-3457, 2018

https://doi.org/10.5194/tc-12-3439-2018-supplement

(C) Author(s) 2018. This work is distributed under

the Creative Commons Attribution 4.0 License.

(c) (1)

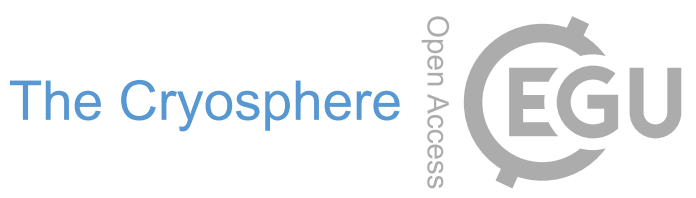

Supplement of

\title{
Ice cliff contribution to the tongue-wide ablation of Changri Nup Glacier, Nepal, central Himalaya
}

Fanny Brun et al.

Correspondence to: Fanny Brun (fanny.brun@univ-grenoble-alpes.fr)

The copyright of individual parts of the supplement might differ from the CC BY 4.0 License. 
Fig. S1 - Map of Changri Nup Glacier showing the extent of the UAV DEMs and the location of the markers used. The background image is the multispectral Pléiades image of November 2016 (copyright : CNES 2016, distribution Airbus D\&S).

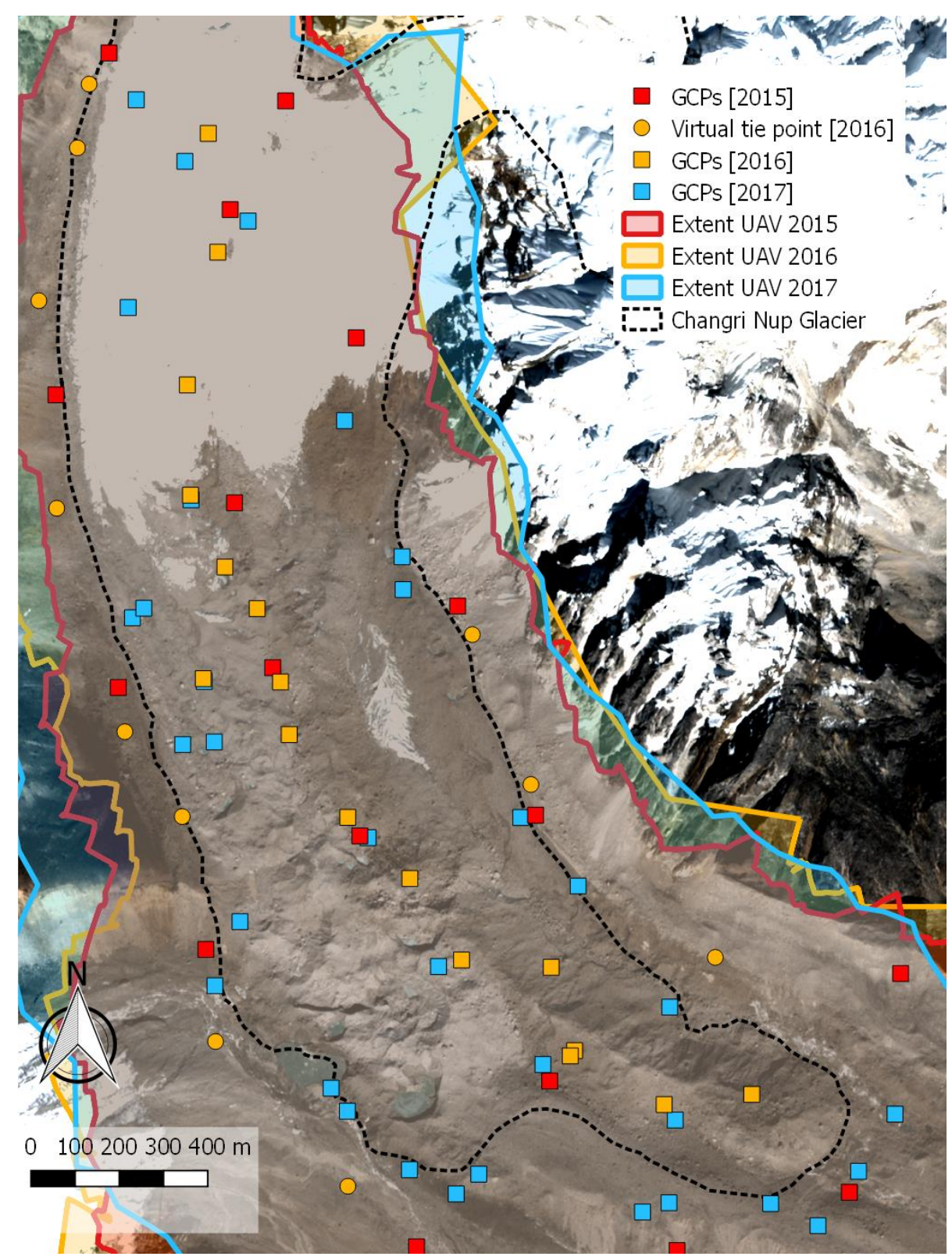


Fig. S2 - Elevation changes on stable terrain from Pléiades DEMs of November 2015 and November 2016 as a function of curvature, slope and aspect.
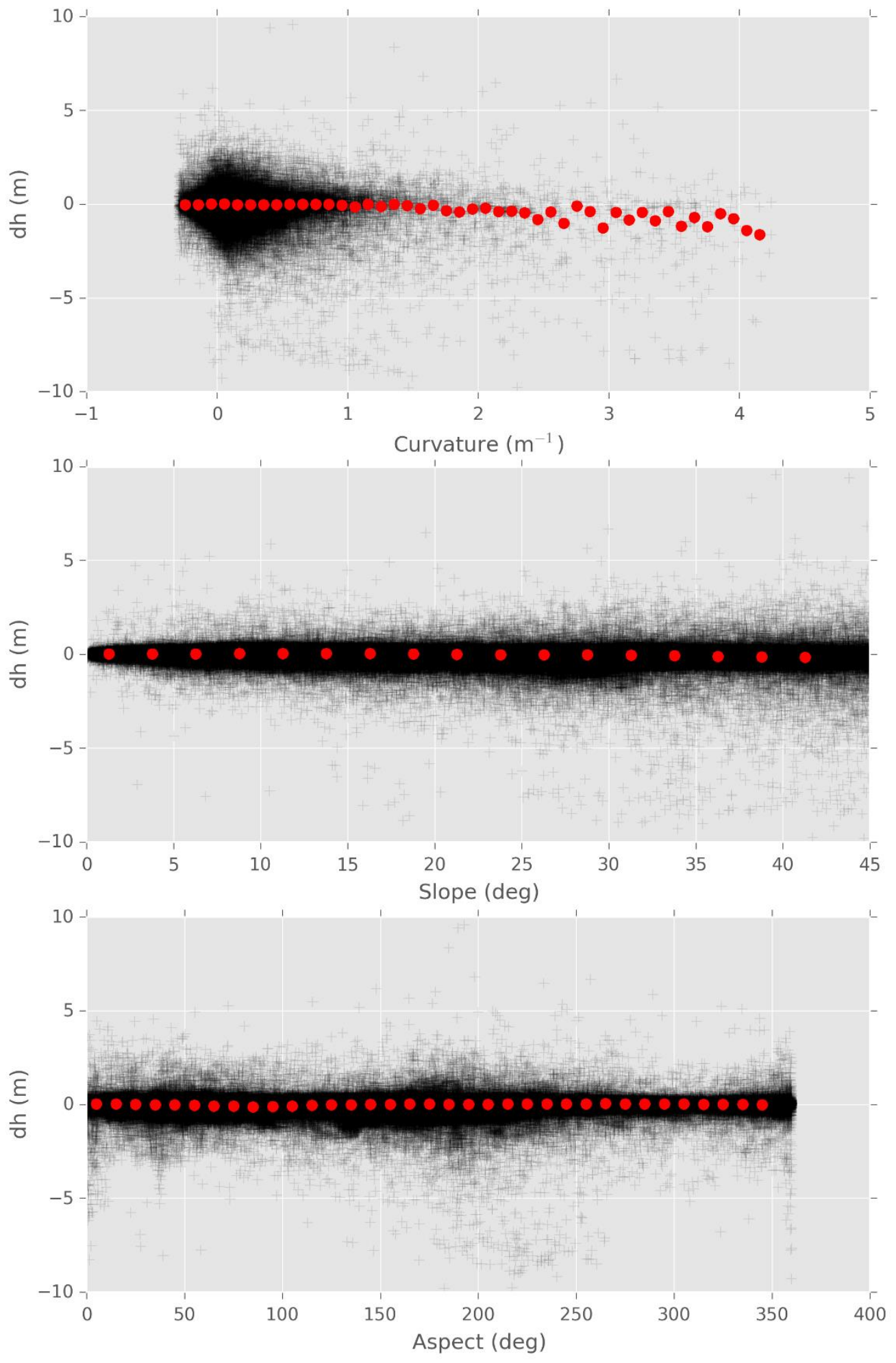
Fig. S3 - Comparison of the field measured velocity with the Pléiades measured velocity. The dashed line is the 1:1 line.

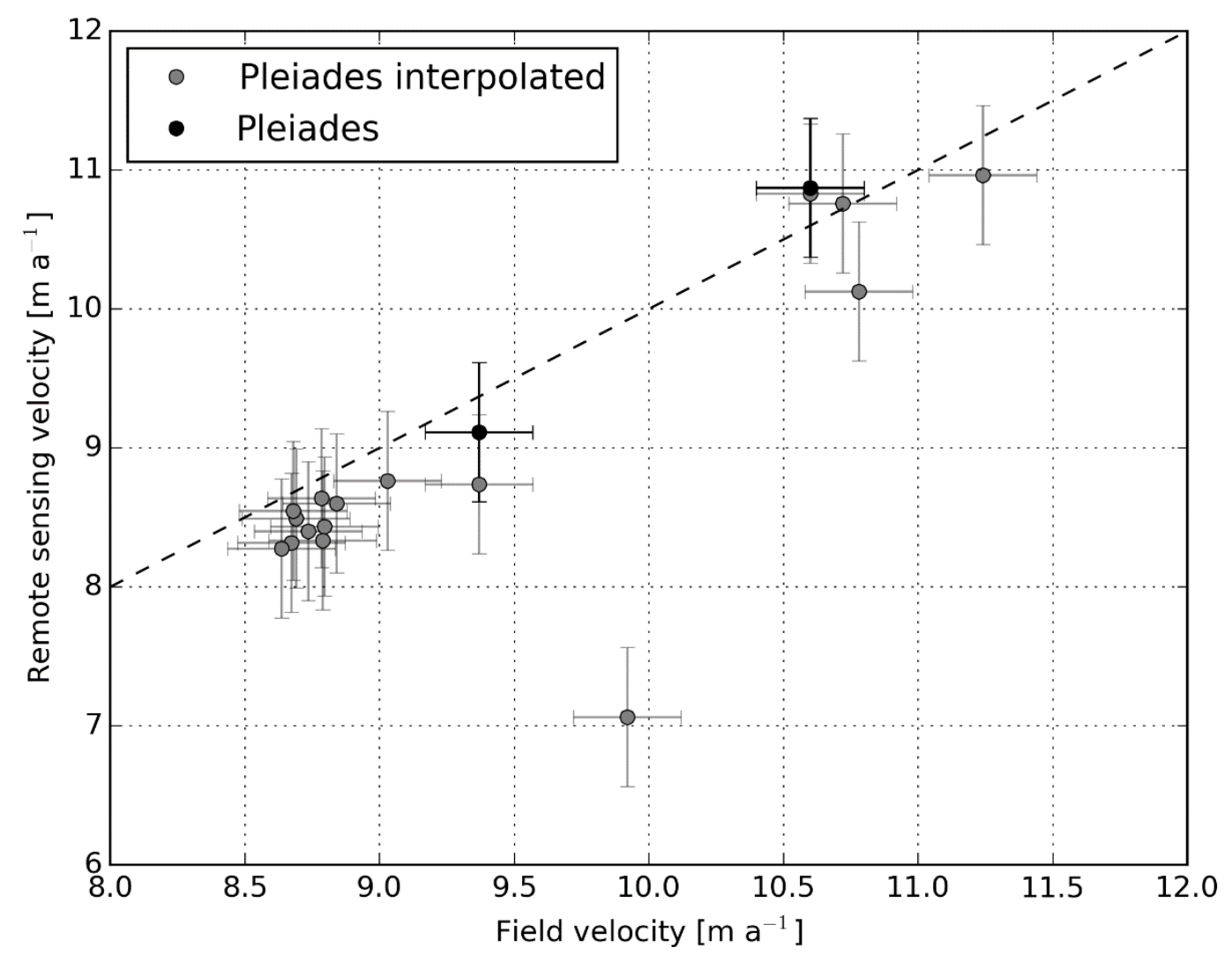


Fig. S4 - Maps of elevation of Changri Nup Glacier (black outline) obtained from the original SRTM DEM (a) and from the SRTM DEM blurred with a five (b), thirty (c) and sixty (d) pixel Gaussian kernel.

a-

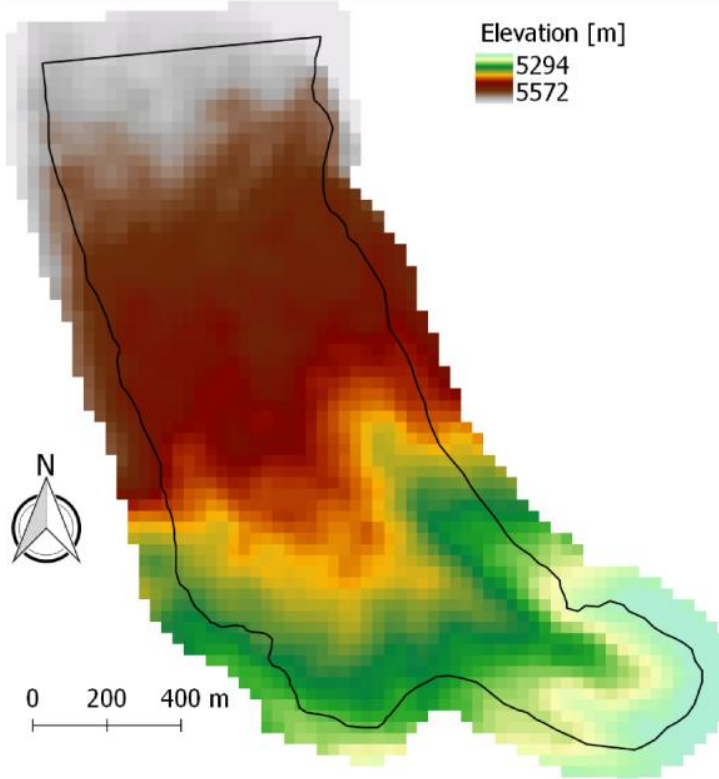

C-

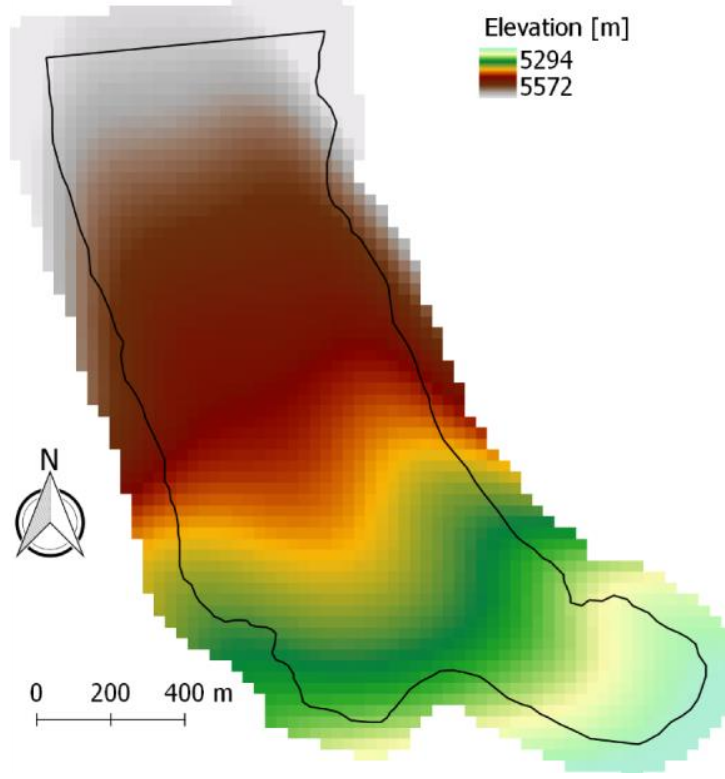

b-

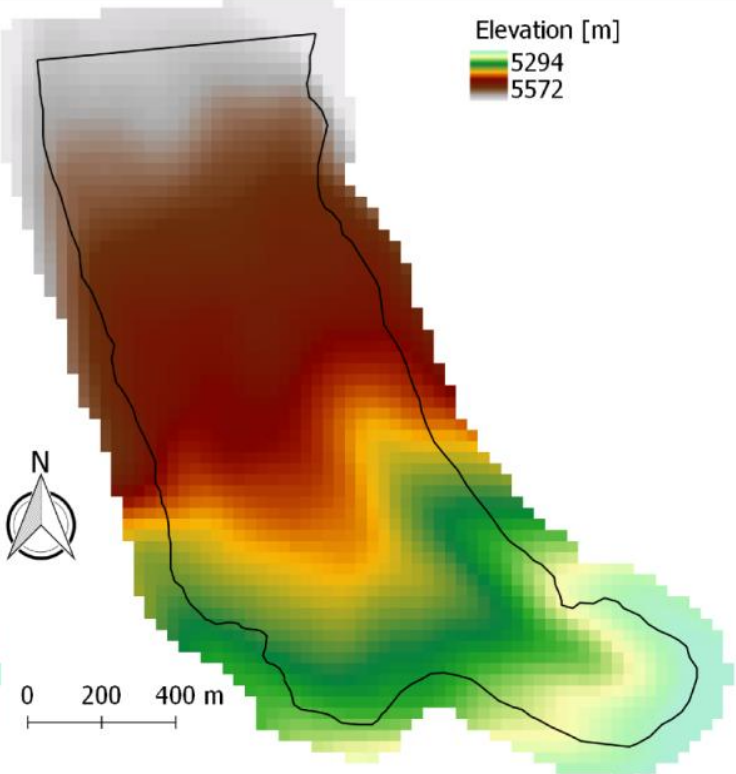

d-

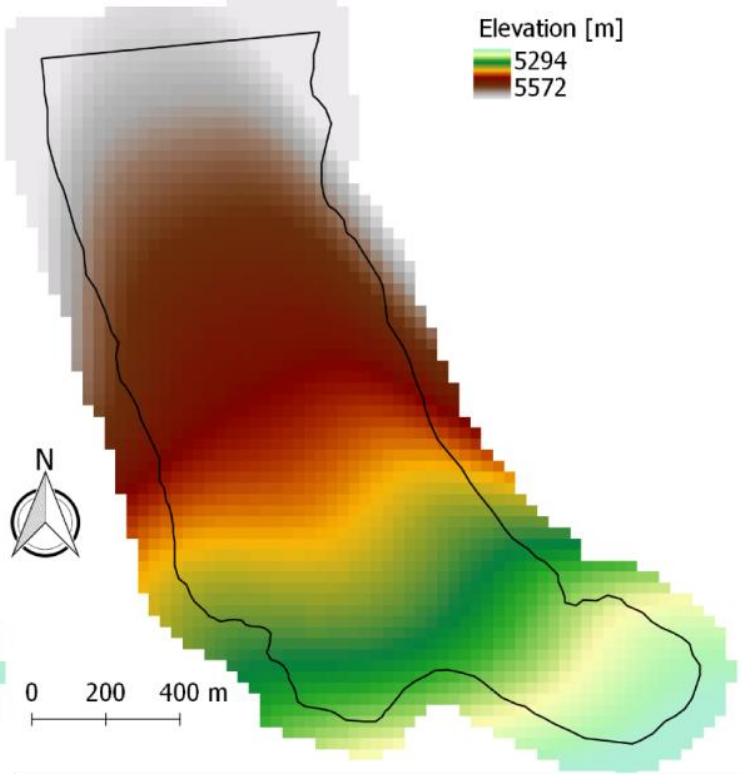


Fig. S5 - Examples of the methodological processing for cliff 05, located on a slow flowing area (left panels) and cliff 11, located in a fast flowing area (right panels). For all the panels the cliff outlines are represented in UTM45/WGS84. a- influence of the glacier flow correction, and comparison with a uniform translation. B- example of analogous points needed for the triangulation regularization. cdifference between the individual cliff outlines and the cliff footprint needed to calculate the cliff contribution for gridded data (DEMs).
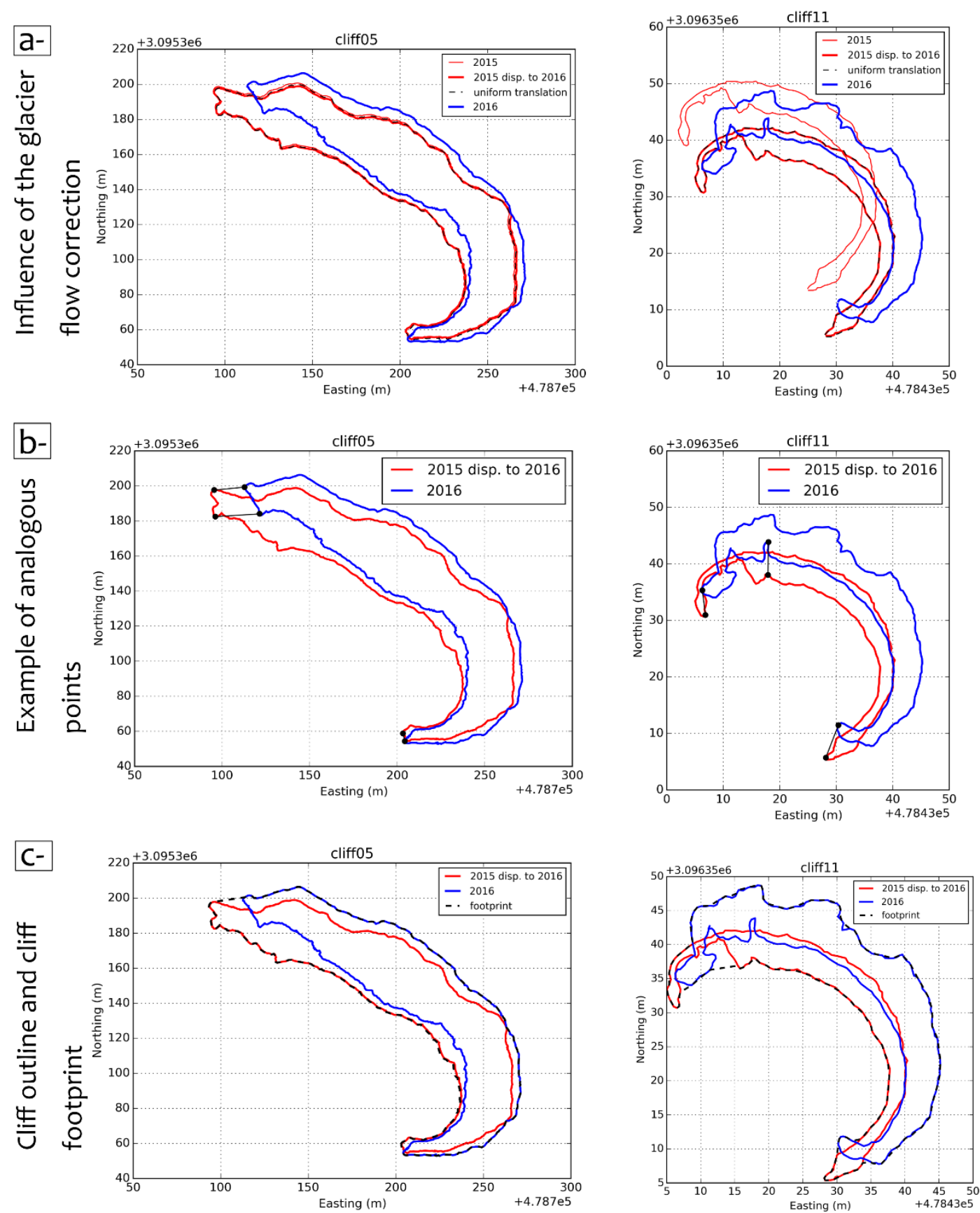
Tab. S1 - Volume loss from the three methods for each cliff

\begin{tabular}{|l|l|l|l|}
\hline Cliff ID & $\begin{array}{l}\text { Volume terrestrial } \\
\text { photogrammetry }\end{array}$ & Volume UAV & Volume Pléiades \\
\hline & {$\left[\mathrm{m}^{3} \mathrm{a}^{-1}\right]$} & {$\left[\mathrm{m}^{3} \mathrm{a}^{-1}\right]$} & {$\left[\mathrm{m}^{3} \mathrm{a}^{-1}\right]$} \\
\hline Cliff 01 & $54066 \pm 12735$ & $51587 \pm 12946$ & $44259 \pm 11303$ \\
\hline Cliff 02 & $5538 \pm 1361$ & $5726 \pm 1664$ & $6464 \pm 1877$ \\
\hline Cliff 03 & $14374 \pm 3486$ & $9460 \pm 3038$ & $10345 \pm 3318$ \\
\hline Cliff 04 & $47771 \pm 11733$ & $49691 \pm 12258$ & $48075 \pm 12066$ \\
\hline Cliff 05 & $5543 \pm 1442$ & $6136 \pm 1767$ & $6802 \pm 1975$ \\
\hline Cliff 06 & $12562 \pm 3020$ & $13224 \pm 3651$ & $13459 \pm 3736$ \\
\hline Cliff 07 & $7146 \pm 1709$ & $7496 \pm 2080$ & $7762 \pm 2169$ \\
\hline Cliff 08 & $29685 \pm 7092$ & $29315 \pm 7635$ & $28748 \pm 7596$ \\
\hline Cliff 09 & $4034 \pm 967$ & $4203 \pm 1167$ & $3838 \pm 1104$ \\
\hline Cliff 10 & $10439 \pm 2559$ & $9143 \pm 2472$ & $10485 \pm 2845$ \\
\hline Cliff 11 & $1398 \pm 386$ & $1747 \pm 595$ & $1000 \pm 431$ \\
\hline Cliff 12 & $899 \pm 350$ & $542 \pm 311$ & $507 \pm 339$ \\
\hline Total & $193453 \pm 19647$ & $188270 \pm 20417$ & $181744 \pm 19436$ \\
\hline
\end{tabular}

Tab. S2 - 3D area changes of the twelve field monitored cliffs

\begin{tabular}{|l|r|r|r|}
\hline Cliff ID & $\begin{array}{l}\text { 3D area } \\
\text { 2015 }\left[\mathrm{m}^{2}\right]\end{array}$ & $\begin{array}{l}\text { 3D area } \\
\text { 2016 }\left[\mathrm{m}^{2}\right]\end{array}$ & $\begin{array}{l}\text { Relative } \\
\text { area } \\
\text { Change (\%) }\end{array}$ \\
\hline Cliff 01 & 6126 & 8961 & 46 \\
\hline Cliff 02 & 1135 & 1496 & 32 \\
\hline Cliff 03 & 3650 & 2415 & -34 \\
\hline Cliff 04 & 1915 & 1788 & -7 \\
\hline Cliff 05 & 11323 & 11265 & -1 \\
\hline Cliff 06 & 4099 & 6435 & 57 \\
\hline Cliff 07 & 749 & 756 & 1 \\
\hline Cliff 08 & 1286 & 1278 & -1 \\
\hline Cliff 09 & 2897 & 1918 & -34 \\
\hline Cliff 10 & 2659 & 2192 & -18 \\
\hline Cliff 11 & 466 & 707 & 52 \\
\hline Cliff 12 & 818 & 732 & -11 \\
\hline Total & 37124 & 39942 & 8 \\
\hline
\end{tabular}

